\title{
Ibn an-Nafis y la circulación cardiopulmonar
}

\author{
Ibn an-Nafis and cardiopulmonary circulation \\ Ma. del Carmen Lacy-Niebla* \\ Instituto Nacional de Cardiología Ignacio Chávez, Ciudad de México, México
}

أبو الحسن علاء الدين علي بن أبي الحزمالخالدي المخزومي القَرشي الدمشقي

Cada vez que leemos y estudiamos la historia de la medicina, encontramos épicas batallas de la humanidad para lograr sanar el cuerpo humano y su espíritu. Desde las historias mitológicas de Esculapio - Asclepio, hijo del dios Apolo, que fue educado por el sabio centauro Quirón, criatura mitológica de la antigua Grecia, hasta nuestros días, con las investigaciones que llevaron a los doctores Ardem Patapoutian originario de Beirut y abrigado por los EE.UU. como refugiado, y David Julius, originario de Nueva York, a ganar el premio Nobel de Fisiología y Medicina en este el 2021. Sus trabajos nos llevan a la compresión de cómo el sistema nervioso siente e interpreta nuestro entorno; cómo la temperatura, el dolor y los estímulos mecánicos se convierten en impulsos eléctricos. Estos descubrimientos de los galardonados del Premio Nobel explican cómo el calor, el frío y el toque pueden iniciar señales en nuestro sistema nervioso. Estos hallazgos han sido precedidos por innumerables investigaciones y teorías, como las derivadas del filósofo René Descartes, quien en el siglo XIX identificó unos posibles hilos conductores que conectan la piel con el cerebro y ante un estímulo doloroso se obtiene una respuesta mecánica inmediata. En 1944 Joseph Erlanger y Herbert Gasser recibieron el Premio Nobel de Fisiología o Medicina por su descubrimiento de ciertas fibras nerviosas sensoriales que reaccionan a estímulos distintos.
De la misma forma, el descubrimiento de la circulación cardiopulmonar tiene una larga historia al pasar de los siglos. Herófilo de Calcedonia (Bitinia, c.335 a.C-280 a.C.) médico griego de la Escuela de Alejandría, fue capaz de establecer la relación que existe con los latidos cardiacos y la percepción del pulso. Herófilo fue uno de los primeros grandes anatomistas y pudo realizar en Alejandría vivisecciones (disecciones del cuerpo humano en una persona con vida) para estudiar anatomía y fisiología. Por infortunio, la mayoría de sus escritos se perdieron en el primer gran incendio de la biblioteca de Alejandría por Julio César. Agnodice, alumna de Herófilo, sobresale en la historia de la medicina como una de las primeras mujeres en ejercer exitosamente como médica, sin embargo, bajo el disfraz de hombre, ya que la práctica médica estaba prohibida a las mujeres so pena de muerte.

Galeno, quien nació en el año 129 o 130 en Pérgamo, hoy Turquía, antes perteneciente al Gran Imperio Romano, fue médico y filósofo. Los conocimientos que emergieron de su práctica médica dominaron la medicina europea por casi 1,300 años, tanto de anatomía como fisiología, farmacología, cuidado de heridas, ortopedia y neurología. Galeno se formó en uno de los más importantes templos dedicados a Esculapio, en las escuelas de Esmirna, Corinto y Alejandría. Realizó numerosas autopsias, sin embargo solo en animales, a él no le fue permitido disecar

\section{Correspondencia:}

*María del Carmen Lacy-Niebla

E-mail: maricarlacy@yahoo.com

1405-9940 / @ 2021 Instituto Nacional de Cardiología Ignacio Chávez. Publicado por Permanyer. Este es un artículo open access bajo la licencia CC BY-NC-ND (http://creativecommons.org/licenses/by-nc-nd/4.0/).

Fecha de recepción: 13-10-2021

Fecha de aceptación: 28-10-2021

DOI: 10.24875/ACM.M21000080
Disponible en internet: 03-01-2022 Arch Cardiol Mex. 2022;92(1):1-4

www.archivoscardiologia.com

CC BY-NC-ND (http://creativecommons.org/licenses/by-nc-nd/4.0/). 
cuerpos humanos. Viajó a Roma y su fama como médico lo llevó a ser considerado ciudadano romano y ser el médico de Marco Aurelio y posteriormente de su hijo Cómodo. Estudió infinidad de especies animales como elefantes, serpientes, jirafas y monos. El mono, por su relativo parecido con los seres humanos, fue su modelo anatómico más estudiado, y estableció que las características anatómicas y funcionales del corazón eran iguales a las del corazón del ser humano. Él establecía que la sangre atravesaba del ventrículo derecho al ventrículo izquierdo por una serie de perforaciones septales invisibles al ojo humano en donde finalmente se mezclaba con el aire y se creaba el espíritu vital, para así distribuirse por el cuerpo. Es por eso que algunas de las ideas de Galeno eran erróneas, sin embargo corrigió algunos errores del conocimiento médico de la época, como el error de Erasistrato, quien aseguraba que las arterias llevaban aire. En la Edad Media, Ios conocimientos de Galeno fueron la base de los estudios en las universidades europeas, sin embargo el obscurantismo menguó el avance de la Medicina. Galeno pensaba que el sistema venoso se separaba del sistema arterial excepto en las perforaciones invisibles del septo.

En el Imperio Bizantino y en el Califato Abasi, a diferencia de Europa, continuaron estudiando y corrigiendo los errores obtenidos de los modelos anatómicos de Galeno.

En el siglo XIII nació el médico Ibn an-Nafis, en Damasco, Siria, entre el año 1210 y 1213 a.C. (Figs. 1 y 2). Su nombre: Ala-al-Din Abu-I-Hasan Ali ibn Abi---Hazam Ibn al Nafis al Qurashi al-Misri al-Shafii. Recibió su entrenamiento médico en Damasco y El Cairo y posteriormente fue profesor de medicina, gozando posteriormente de gran fama como médico. Uno de sus biógrafos, Masalik al-Absar fi Mamalik al-Amsarde Ibn Fadl Allah al-Umari (d.1349) habla de muchos de los detalles de su vida, personalidad y trabajo. En Damasco estuvo bajo la tutela de Muhadhdhib al-Din alDakhwar. An-Nafis fue un líder en la ciencia y en la medicina y nadie se comparaba con su sagacidad para el estudio y la investigación. Escribió entre muchos otros, un libro de oftalmología y un comentario al $\mathrm{Ca}$ non de Medicina de Avicena. Escribía de memoria sin consultar libros para ello. Escribió sobre jurisprudencia, lógica, medicina y leyes en árabe. Sus biógrafos 10 describen como un hombre alto, de cara ovalada, muy bien educado y de buenas maneras. Al momento de su muerte, gravemente enfermo, sus médicos le sugirieron que tomara vino para morir en paz, a lo que se

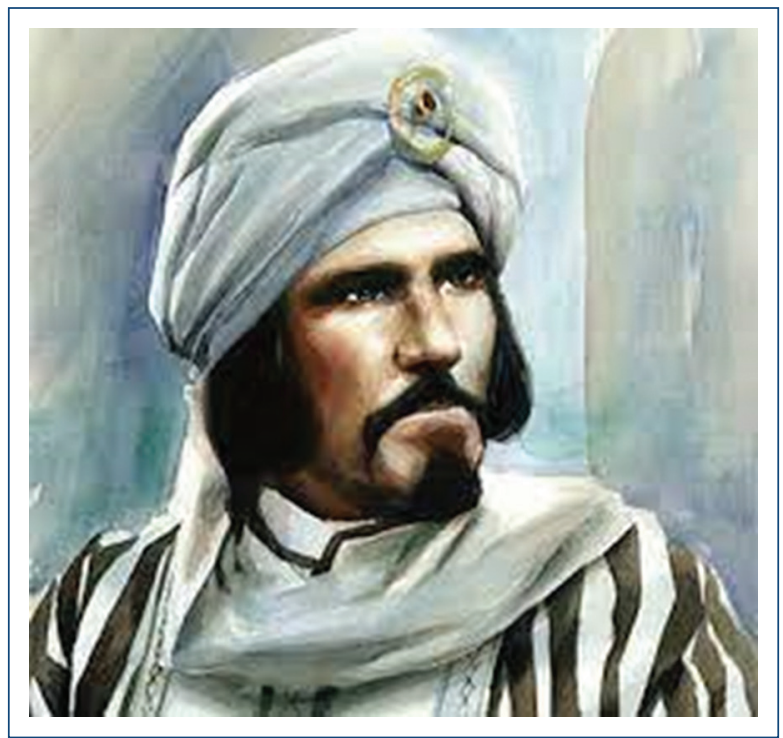

Figura 1. Ibn an-Nafis.

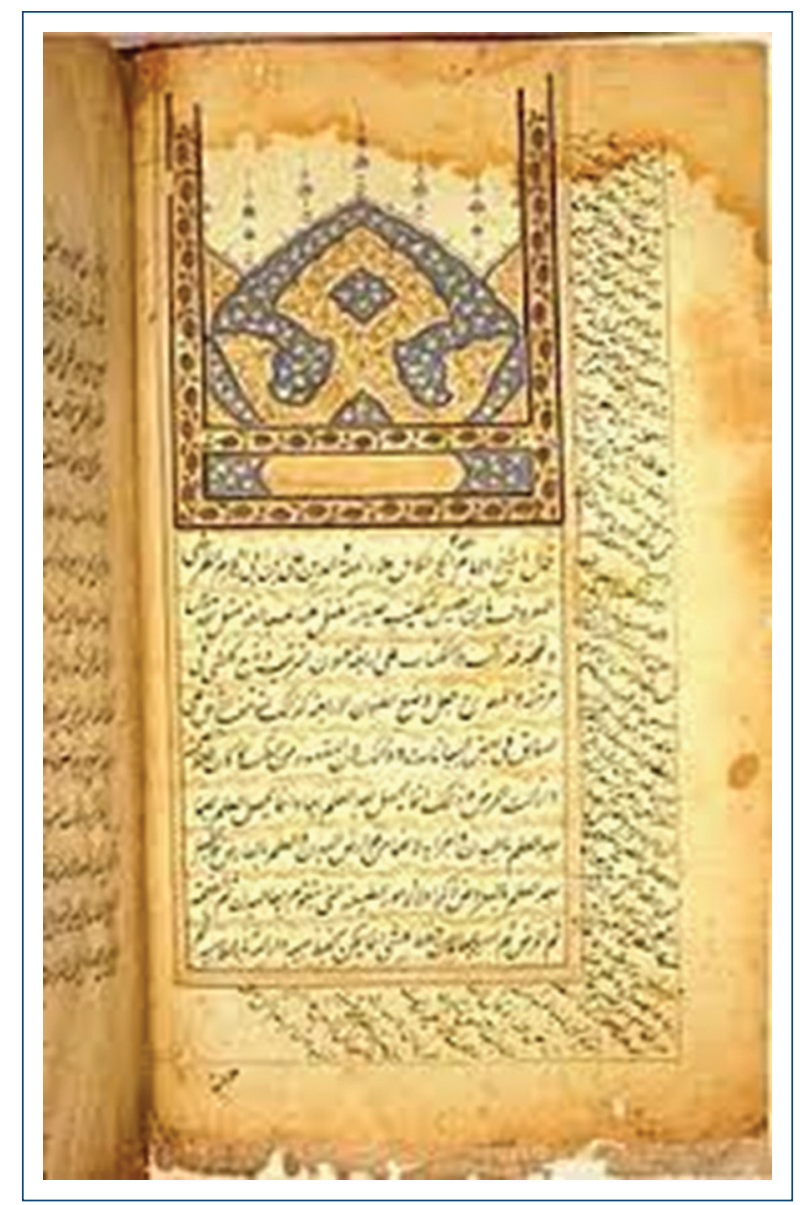

Figura 2. Escritos de Ibn an-Nafis.

negó alegando que no encontraría a Alláh, El Más Grande, con vino en su cuerpo. 
Ejerció la medicina en el hospital Al-Nouri y también fue teólogo, jurisprudente y literato. En el año 1236 viajó a Egipto, en donde sobresalió por ser el médico del sultán y por dirigir como jefe médico los hospitales de Al Nasri y de Al-Mansouri. En el Cairo se construyó una casa con una gran entrada de mármol, aunque nunca se casó.

Los escritos conservados de Galeno fueron criticados duramente por él, a diferencia de los grandes médicos árabes que le precedieron, que eran galenistas. Se menciona que un día acudió a un baño público y, mientras se bañaba, salió del baño, pidió papel y lápiz y escribió un tratado del pulso; al terminar de escribir, volvió a terminar su baño. Lo conocían como «el Segundo Avicena».

Ibn an-Nafis escribió, como comentaba anteriormente, varios libros: Comentario del Canon Completo de Avicena, Un libro de Comprensión del Arte de la Medicina, El Libro Perfecto de Oftalmología, un Libro de Referencia para Médicos, Una Elección de Alimentos y muchos otros libros médicos. En otro trabajo, el Sharh tashrih ibn Sina (Explicación de la Disección de Avicena) escribió un comentario de la anatomía del Canon, en donde realizó su famosa contribución del descubrimiento de la circulación pulmonar.

En el siglo XX, en el año 1924, Muhyi ad-Din at-Tatawi, médico egipcio, descubrió, mientras estudiaba la historia de la medicina árabe en la Universidad Albert Ludwig en Alemania, un escrito en la Biblioteca Estatal Prusiana de Berlín, Comentario de la Anatomía del Canon de Avicena, redactado en árabe. El documento se refiere a los conocimientos árabes antiguos de anatomía, fisiología y patología, y lo sorprendente fue encontrar la primera descripción de la circulación cardiopulmonar tal cual la conocemos hoy en día.

Muhyi ad-Din at-Tatawi presentó ante el grupo médico de Freiburg parte de su tesis doctoral: M. Tatawi, Der Lungenkreilauf mach Al-Koraschi, Disertación Inicial, Freiburg 1924 (La circulación pulmonar de acuerdo con Al-Koraschi).

Al-Qurashi es uno de los nombres con que se conoce a an-Nafis.

El estudio de la medicina islámica nos demuestra que la mayoría de los manuscritos disponibles aún no han sido editados y mucho menos traducidos. Además, un gran número de estos manuscritos se perdieron como resultado de la invasión mongólica en el año 1258.

Los amplios conocimientos anatómicos que lbn an-Nafis tenía lo llevaron a describir la circulación cardiopulmonar, en donde las referencias indican que escribió: «Una vez que la sangre que ha llegado a esta cavidad (ventrículo derecho), tiene que ser enviada a la cavidad izquierda, donde se genera el espíritu vital. Pero no hay comunicación entre las dos cavidades, ya que la materia del corazón es sólida en esta región y no tiene ni un conducto visible que habían pensado algunas personas, ni uno invisible que podría permitir la transmisión de la sangre como fue establecido por Galeno. Los poros del corazón ahí están cerrados y su substancia es gruesa. Por lo tanto, la sangre, después de haber sido refinada, debe alcanzar la vena arteriosa (arteria pulmonar) a los pulmones, con el fin de expandirse en su volumen y poder ser mezclada con el aire de tal forma que sus partículas más finas puedan ser clarificadas y alcanzar la arteria venosa (vena pulmonar), de donde es transmitida a la cavidad izquierda del corazón. Esto, después de haber sido mezclada con el aire y haber obtenido la aptitud de generar el espíritu vital. La parte de la sangre que es menos refinada se utiliza por los pulmones para su nutrición».

No existe ninguna duda de que Ibn an-Nafis describió la circulación pulmonar y además mostró un grado muy alto de originalidad al negar la existencia de los forámenes descritos por Galeno entre los dos ventrículos, y una valentía incomparable al contradecir los escritos del gran maestro de la medicina.

Miguel Servet, teólogo y científico español del siglo $X V I$, estableció que: «El espíritu vital tiene su origen en el ventrículo izquierdo y los pulmones lo asisten en su generación. Se genera en los pulmones de una mezcla de aire inspirado con sangre producida que el ventrículo derecho envía al ventrículo izquierdo. Sin embargo esta comunicación no se lleva a cabo a través del muro medial del corazón, como es comúnmente creído, sino por un circuito muy ingenioso, la sangre pasa a los pulmones por un circuito largo".

William Harvey, fisiólogo inglés de los siglos XVI y XVII, perteneció al Royal College of London. Trabajó en St. Bartholomew's Hospital y se casó con Elizabeth Browne, hija del médico personal del Rey Jaime I. El 17 de abril de 1616, Harvey mostró a los miembros del Royal College of Physicians su revolucionaria teoría sobre la circulación de la sangre, en donde el corazón funciona como una bomba que expele la sangre que no se origina en el hígado a partir de los líquidos y alimentos ingeridos en forma constante, como se pensaba desde la época de Galeno. En 1628 publicó un libro de 72 páginas llamado Excertitatio anatomica motu cordis et sanguinis in animabilus, conocido como el Motu Cordis. Harvey demuestra 
definitivamente que los conceptos que permanecieron como ciertos durante siglos estaban equivocados.

Hombres fuertes y valientes, lograron demostrar el circuito de la circulación sanguínea después de muchos siglos de obscurantismo. Si durante los siglos XIII, XIV, XV y XVI se hubiesen conocido y aceptado los conocimientos y sabiduría árabe, el progreso de la medicina tendría otra historia que contar.
Ib an-Nafis, extraordinario médico árabe, debe ser considerado el padre de la fisiología de la circulación sanguínea. A su nombre están unidos entonces los nombres de Miguel Servet y William Harvey por sus grandes aportaciones al conocimiento de la circulación sanguínea.

Dra. María del Carmen Lacy Niebla Ciudad de México, octubre 2021. 